\title{
Freeze-Thaw Risk in Solid Masonry: Are 'Hygrothermal Response Based' Analyses Mandatory when Studying the Sensitivity of Building Envelopes to Climate Change?
}

\author{
Isabeau Vandemeulebroucke ${ }^{1}$, Steven Caluwaerts ${ }^{2}$ and Nathan Van Den Bossche ${ }^{1}$ \\ ${ }^{1}$ Building Physics Group, Department of Architecture and Urban Planning, Ghent University, \\ Belgium, isabeau.vandemeulebroucke@ugent.be. \\ ${ }^{2}$ Atmospheric Physics Group, Department of Physics and Astronomy, Ghent University, Belgium, \\ steven.caluwaerts@ugent.be.
}

\begin{abstract}
The 5th Assessment Report of the Intergovernmental Panel on Climate Change (IPCC) reports important evolutions in the climate system. These changes are likely to affect the durability of the built environment. Although many contemporary studies investigate the future energy efficiency of buildings, research on the impact of climate change on the hygrothermal behaviour and degradation of building envelopes is rather scarce. Using climate projections, we studied the advantage of 'hygrothermal response based' analyses over 'climate based' analyses when assessing the impact climate change on façades. This paper presents a sensitivity study on solid masonry wall assemblies, before and after internal retrofitting, using three RCP (Representative Concentration Pathways) projections of the ALARO-O Regional Climate Model at the grid point of Brussels (BE). The findings suggest the necessity of a 'hygrothermal response based' analysis to study the sensitivity of the building envelope to climate change. Moreover, the largest sensitivity is observed for RCP 8.5, the scenario having the highest projected greenhouse gas concentrations by the end of the century.
\end{abstract}

Keywords: Hygrothermal Response, Building Envelope, Climate Change, HAM Simulation, Masonry.

\section{Introduction}

The Fifth Assessment Report of the Intergovernmental Panel on Climate Change reports significant changes in the climate system (IPCC, 2014). Since pre-industrial times the global surface temperature has increased ca. $1^{\circ} \mathrm{C}$, and is projected to rise further during the $21 \mathrm{st}$ century. Along with that, extreme events are influenced by the increased greenhouse gas (GHG) emission in our atmosphere. Across Europe, heat waves and extreme precipitation are likely to become more frequent, more intense and separated by longer periods of drought, and the number of freezing days is likely to decrease (IPCC, 2014).

The built environment will be significantly affected by climate change (de Wilde and Coley, 2012; Fatorić and Seekamp, 2017). Many studies focus on the energy efficiency of our building stock regarding climate change. This study investigates the climate sensitivity of retrofitting strategies of historical buildings to increase their thermal resistance and airtightness. As exterior retrofitting of heritage buildings is often not allowed due to the façade's historical value, interior retrofits may be the only solution to improve the energy efficiency of the building envelope (Straube and Schumacher, 2010). Studies on the durability of internally retrofitted solid masonry show that this strategy might increase the risk of moisture-related damages, as freezethaw action. However, few studies investigate the impact of climate change on the long term 
durability of these retrofits, and there is no sound methodology to implement climate projections in Heat Air Moisture (HAM) simulations.

This paper aims to study the difference between a 'climate based' and 'hygrothermal response based' analysis when assessing the freeze-thaw risk in solid masonry, before and after internal retrofit, with regards to climate change.

\section{Methodology}

The 1-dimensional HAM simulations in this study are performed in Delphin 5.9.5, which has been successfully benchmarked in the past by the HAMSTAD Benchmark exercises a.o. (Nicolai, Grunewald and Zhang, 2007).

\subsection{Climatological Conditions}

This work applies the 4-km resolution ALARO-0 Regional Climate Model (RCM) data of the CORDEX.be project (Termonia et al., 2018) to investigate the climate impact. Climate data for the period 1950-2100 are selected for the Uccle gridpoint. For the period 1950-2005 the historical run will be used, while for the 2006-2100 timeframe different climate projections forced by scenarios for future GHG emissions are considered to investigate the climate sensitivity. The Representative Concentration Pathways used in this study are RCP 2.6, RCP 4.5 and RCP 8.5, representing respectively a low, intermediate and high radiative forcing (IPCC, 2014).

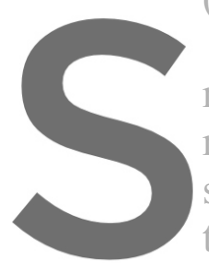

The modelled mete relative humidity, wind radiation and downware systematic biases. As th the HAM simulations to
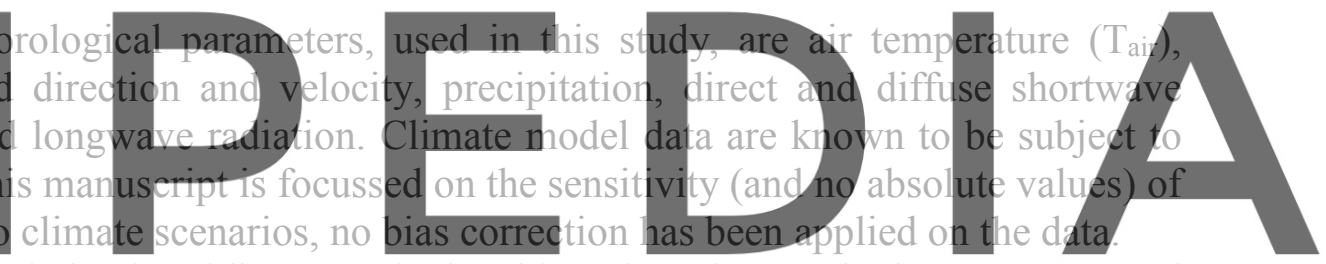

The indoor $\mathrm{T}_{\text {air }}$ and relative humidity are calculated based on the standard ISO 13788, and

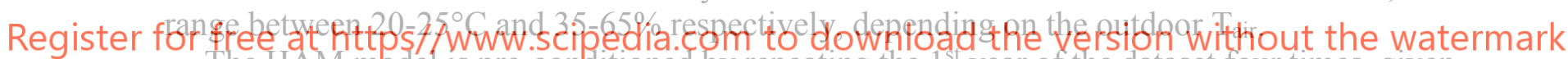
The HAM model is pre-conditioned by repeating the $1^{\text {st }}$ year of the dataset four times, given this year does not represent extremes. The conditioning years are not part of the evaluation.

\subsection{Wall Assemblies}

Two variants of a solid masonry wall assembly are considered. In both cases the masonry has a width of $300 \mathrm{~mm}$, and is selected from the Delphin Material Library, i.e. 'Historical Brick Cluster 4'. The original wall assembly is finished with $12 \mathrm{~mm}$ of gypsum plaster (interior). The second masonry wall (without plaster) is retrofitted at the interior with mineral wool $(150 \mathrm{~mm})$, open vapour barrier $(\mathrm{sd}=2.3 \mathrm{~m})$ and gypsum board $(12 \mathrm{~mm})$. The masonry is assumed homogenous brick, as this simplification is found acceptable by Vereecken and Roels (2013).

The critical degree of moisture saturation for freeze-thaw damage to occur, is not known for the selected brick material. Therefore, the arbitrary value of $25 \%$ ice volume rate is used (Straube, Schumacher, \& Mensinga, 2010). The critical moisture content $\left(\mathrm{MC}_{\text {crit }}\right)$ for the masonry is $82.5 \mathrm{~kg} / \mathrm{m}^{3}$. Note that this is a conservative value, considered as worst-case scenario. 


\subsection{HAM Simulations}

Five situations are analysed: i) the original solid masonry wall facing the south-west (SW) $\left(225^{\circ}\right)$, the prevailing wind-driven rain (WDR) direction in Uccle, for RCP 8.5, ii-iv) the retrofitted wall facing SW for RCP 2.6, 4.5 and 8.5, and v) the retrofitted wall facing the northwest $(\mathrm{NW})\left(315^{\circ}\right)$ for RCP 8.5 , to study an orientation receiving less solar radiation and a smaller WDR load.

The climate data and simulation results are analysed using the moving average per period of 30 years. All simulation results are analysed at a depth of $5 \mathrm{~mm}$ in the masonry (exterior side), as this is generally a critical depth for freeze-thaw action (Vandemeulebroucke et al. 2019).

\section{Results}

\section{1 'Climate Based' Analysis}

The moving average of the annual mean air temperature ( $T_{\text {air,mean,annual }}$ ) confirms the warming trend over the 21 st century especially for RCP 4.5 and 8.5 , illustrated by the dotted lines in Figure 1(IPCC, 2014). For the RCP 2.6 scenario which assumes strong mitigation measures, the temperature reaches a maximum around 2050. The warming over the whole period is ca.

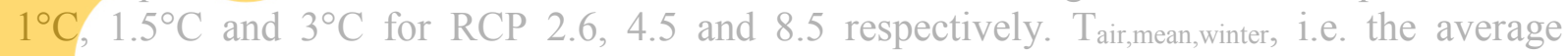
temperature during the period December-January-February, confirms the temperature trends. Analysed frost indices are the annual hours of frost and the number of freeze-thaw cycles based

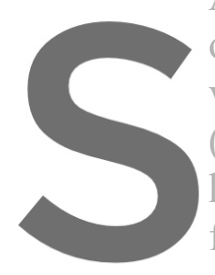

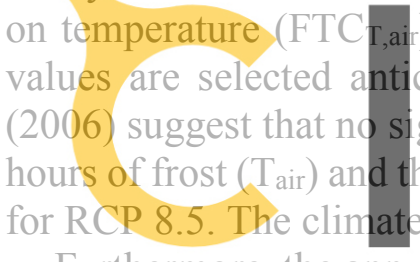
ii), considering freezin
icipating the "response
sificant freeze-thaw
the number of $\mathrm{T} \mathrm{C}_{\mathrm{T}}$,air
te change signal for $\mathrm{RC}$
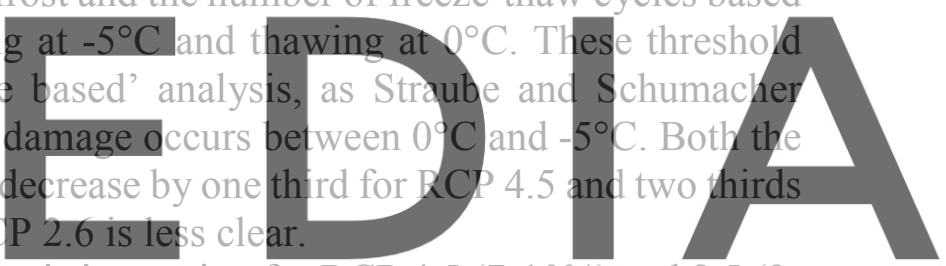

Furthermore, the annual precipitation amount is increasing for RCP 4.5 (7-10\%) and 8.5 (9-

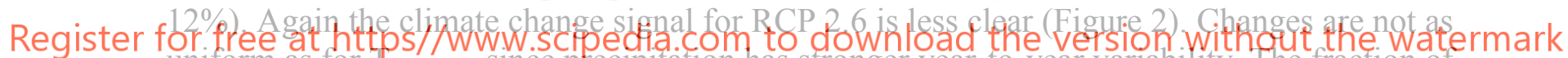
uniform as for 1 air,mean, since precipitation has stronger year-to-year variability. The fraction of annual precipitation occurring in winter is ca. $25 \%$ and increases by $0-4 \%$ for RCP 4.5 and 8.5 .

The other climate variables, e.g. as wind direction and velocity, show only small changes over the course of the 21 st century (not illustrated here).

\section{2 'Response Based' Analysis}

The 'response based' analysis indicates that the mean temperature at $5 \mathrm{~mm}$ in the masonry ( $\mathrm{T}_{5 \mathrm{~mm}, \text { mean }}$ ), illustrated by the solid lines in Figure 1, follows the same trend as the $\mathrm{T}_{\text {air,mean. }}$ However, the offset between the climate data and the simulated response of the masonry differs per season, wall assembly and orientation, ranging between $-0.3^{\circ} \mathrm{C}-2.2^{\circ} \mathrm{C}$. The offset slightly decreases towards the end of the 21st century. Except for the retrofitted walls in winter, $\mathrm{T}_{5 \mathrm{~mm} \text {,mean }}$ is higher than $\mathrm{T}_{\text {air,mean }}$. The highest values are observed for the original wall for RCP 8.5 due to the lack of thermal insulation. The differences between the climate and response data are smaller in winter compared to the rest of the year. Whereas wall surfaces can heat up to temperatures higher than $40^{\circ} \mathrm{C}$ due to shortwave radiation, these surfaces are cooled down below $\mathrm{T}_{\text {air }}$ due to longwave radiation exchange with the sky hemisphere. Besides, the heat capacity of the brick masonry and embedded moisture both influence the $T_{5 \mathrm{~mm}}$. Therefore, the 
hours of frost (threshold of $0^{\circ} \mathrm{C}$ ) and the number of $\mathrm{FTC}_{\mathrm{T}}$ (freezing at $-5^{\circ} \mathrm{C}$ and thawing at $0^{\circ} \mathrm{C}$ ) differ between the climate data (based on $\mathrm{T}_{\text {air) }}$ and simulation results (based on $\mathrm{T}_{5 \mathrm{~mm}}$ ), but also between the individual situations (Figure 1).

The hours of frost and $\mathrm{FTC}_{\mathrm{T}}$ at $5 \mathrm{~mm}$ depth in the masonry follow the decreasing trend of the climate data for RCP 4.5 and 8.5 (Figure 1). Here, the offset between the climate and simulated results ranges between $-25 \%-20 \%$, and $-57 \%-6 \%$, respectively for both indices. The hours of frost $\left(\mathrm{T}_{5 \mathrm{~mm}}\right)$ is the highest for the retrofitted SW-wall, whereas the retrofitted NWwall entails almost equal values compared to the climate data. The hours of frost $\left(T_{5 \mathrm{~mm}}\right)$ is the lowest in the original wall. Moreover, the number of $\mathrm{FTC}_{\mathrm{T}, 5 \mathrm{~mm}}$ is the highest for the retrofitted $\mathrm{NW}$-wall during the historical period. Whereas later on, the retrofitted NW-wall is similar to the retrofitted SW-wall, for RCP 8.5. The number of $\mathrm{FTC}_{\mathrm{T}, 5 \mathrm{~mm}}$ is the lowest for the original wall. Differences become smaller towards the end of the century.
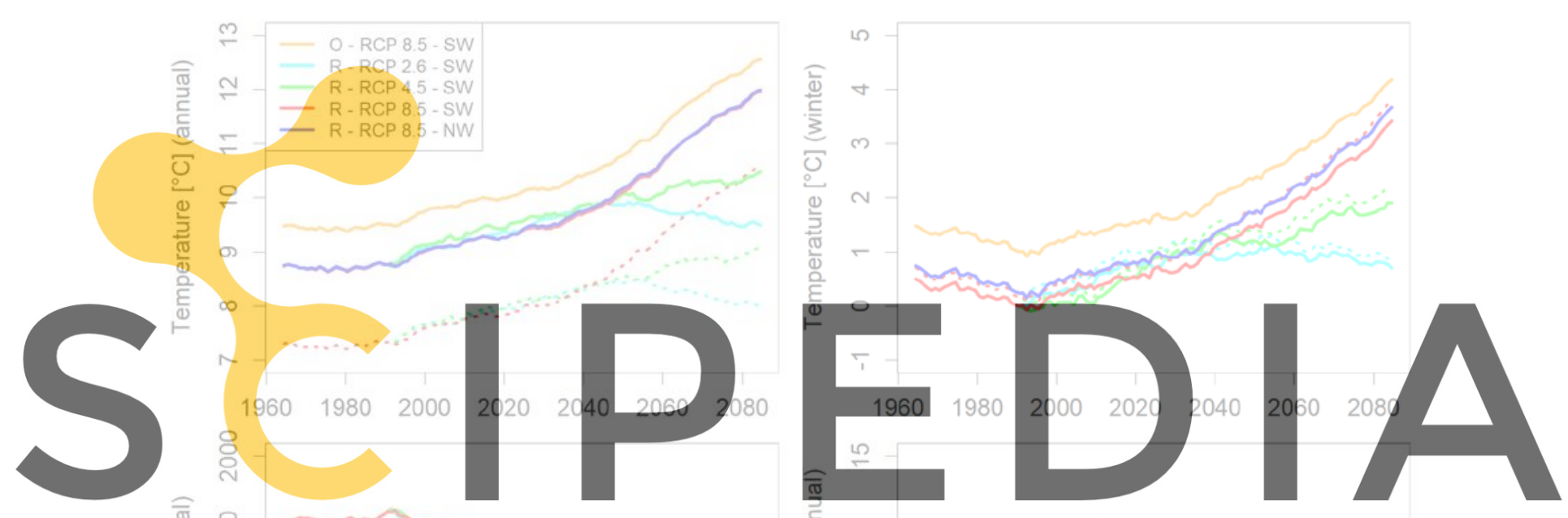

Register för free at https//wWw.scipedia.com to download the version without the watermark
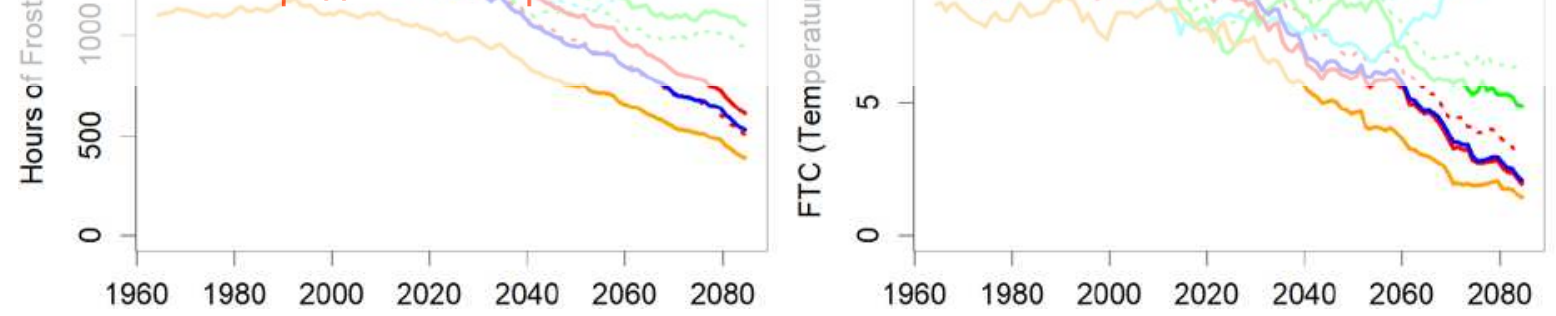

Figure 1. Moving average of the annual mean temperature (top, left), the mean temperature in winter (top, right), the annual hours of frost (bottom, left) and the annual number of FTC (freezing $-5^{\circ} \mathrm{C} /$ thawing $0^{\circ} \mathrm{C}$ ) (bottom, right) at $5 \mathrm{~mm}$ depth in the masonry (O: original, $\mathrm{R}$ : retrofitted). The dotted lines present the air temperature climate data (cyan: RCP 2.6, green: RCP 4.5 and red: RCP 8.5).

To analyse the moisture management, WDR load and moisture content at $5 \mathrm{~mm}$ depth $\left(\mathrm{MC}_{5 \mathrm{~mm}}\right)$ are evaluated. The drying potential is outside the scope of this paper. The WDR load depends on a complex relation between precipitation, wind velocity and wind direction, but also on catch ratio, height and wall orientation a.o. (Blocken and Carmeliet, 2010). As expected, the order of magnitude between the precipitation ('climate based') and WDR load ('response based') differs significantly (Figure 2). Besides, there is a large difference in WDR load 
between the two orientations. As there is no significant climate change signal for wind direction and velocity, the increase in annual WDR load for the SW-orientation can be related to the increasing precipitation. For the NW-orientation, the WDR load remains low and there is no clear climate change signal. Analysing the percentage of precipitation and WDR load in winter, there can be observed that the percentage is significantly higher for the SW-WDR load (+$40 \%$ ), than the precipitation amount (+-25\%) (Figure 2$)$. For a given precipitation amount, the percentage SW-WDR load in winter is higher because of higher wind velocities during this season. Both the precipitation and WDR load illustrate an increase in percentage during the winter, meaning that the climate change signal is not constant over the year.

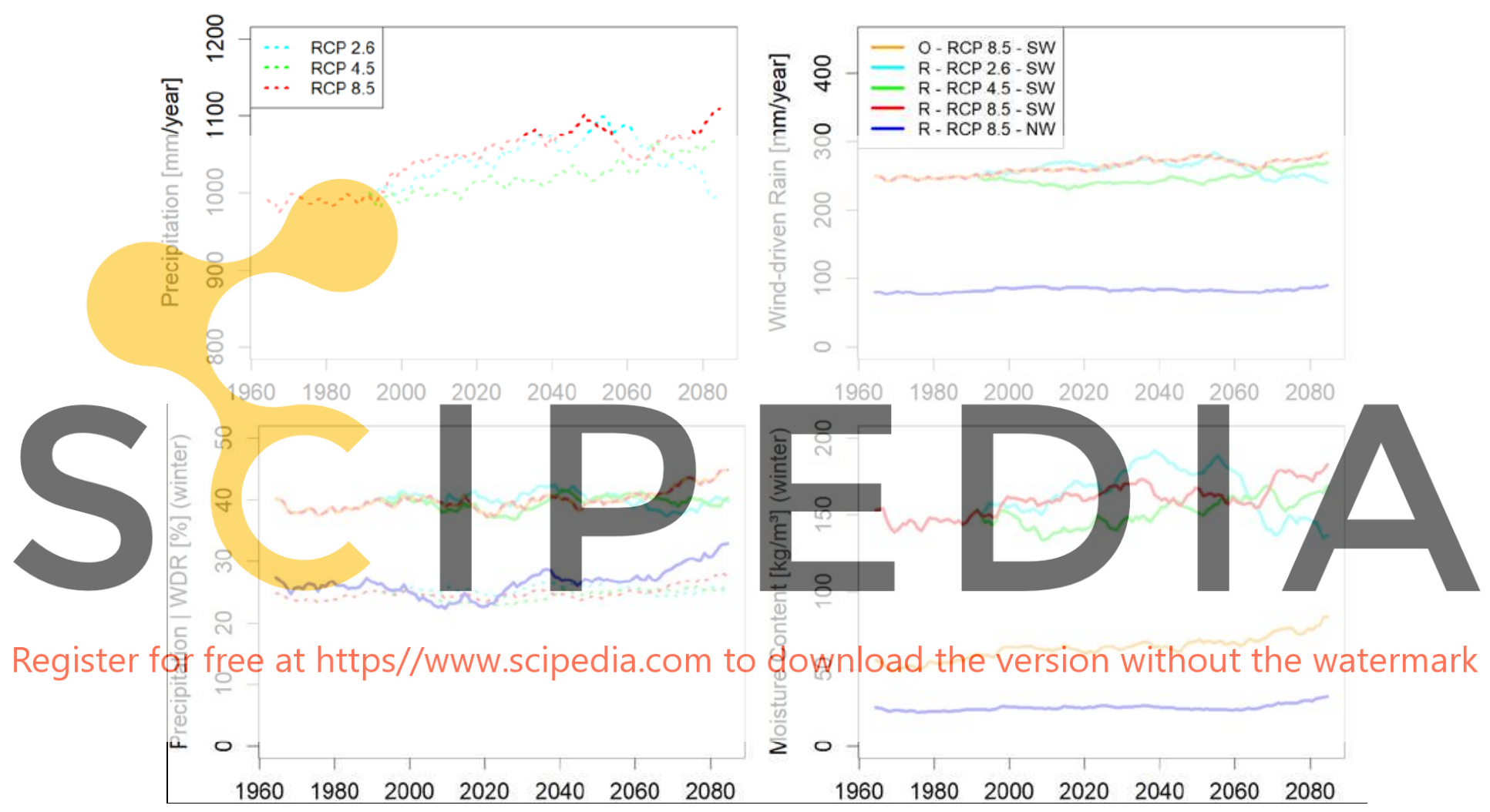

Figure 2. Moving average of the annual precipitation (top, left), the annual wind-driven rain load (top, right), the fraction of annual precipitation or WDR occurring in winter (bottom, left) and the moisture content in winter at 5 $\mathrm{mm}$ depth in the masonry (bottom, right) (O: original, R: retrofitted). The dotted lines illustrate the climate data (cyan: RCP 2.6, green: RCP 4.5 and red: RCP 8.5).

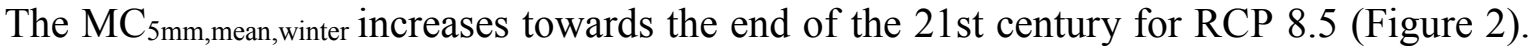
Especially for the original wall, which is SW orientated, and the retrofitted SW-wall, there is a clear climate change signal. The difference between the wall assemblies is significant. The

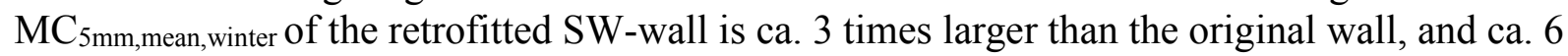

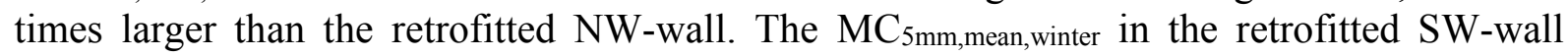
exceeds the $\mathrm{MC}_{\text {crit }}$ for all three RCP projections.

Please note that the differences between the individual RCP projections for the WDR load and $\mathrm{MC}$, considering the retrofitted SW-wall, are smaller than the differences between the wall assemblies and orientations (Figure 2). This means that the uncertainty about the WDR load 
and $\mathrm{MC}$ induced by the variation in wall assembly and orientation is significantly larger than the uncertainty induced by the RCP projections.

Furthermore, the number of $\mathrm{FTC}_{\mathrm{T}, 5 \mathrm{~mm}}$ cannot be directly compared to the $\mathrm{FTC}_{\text {crit, } 5 \mathrm{~mm}}$ in the masonry, as the latter is related to both the temperature and moisture saturation degree in the pore matrix. However, the trend lines of both indices are analysed. As for the hours of frost $\left(\mathrm{T}_{5 \mathrm{~mm}}\right)$ and $\mathrm{FTC}_{\mathrm{T}, 5 \mathrm{~mm}}$, a decreasing trend in number of $\mathrm{FTC}_{\text {crit }, 5 \mathrm{~mm}}$ is observed for RCP 4.5 and 8.5, but this trend is less pronounced (Figure 1 and 3 ). Although the number of $\mathrm{FTC}_{\mathrm{T}, 5 \mathrm{~mm}}$ in the retrofitted NW-wall (RCP 8.5) is the highest in comparison to the other situations (Figure 1), the number of $\mathrm{FTC}_{\text {crit }, 5 \mathrm{~mm}}$ is the lowest for that wall and remains close to zero (Figure 3). The number of $\mathrm{FTC}_{\text {crit }, 5 \mathrm{~mm}}$ for the retrofitted SW-wall in RCP 8.5, on the other hand, is the highest amongst the different situations for the three RCP's. The climate change signal shows a decrease of $20 \%$ and $45 \%$ for RCP 4.5 and 8.5 , respectively. The original wall (RCP 8.5) displays a significantly lower number of $\mathrm{FTC}_{\text {crit }, 5 \mathrm{~mm}}$, but higher than the retrofitted NW-wall. No clear climate signal is observed for the original wall. Additionally, Figure 2 illustrates the number of $\mathrm{FTC}_{\text {crit }, 5 \mathrm{~mm}}$ per year. Please note that the annual variation is very large, even for the original wall assembly.
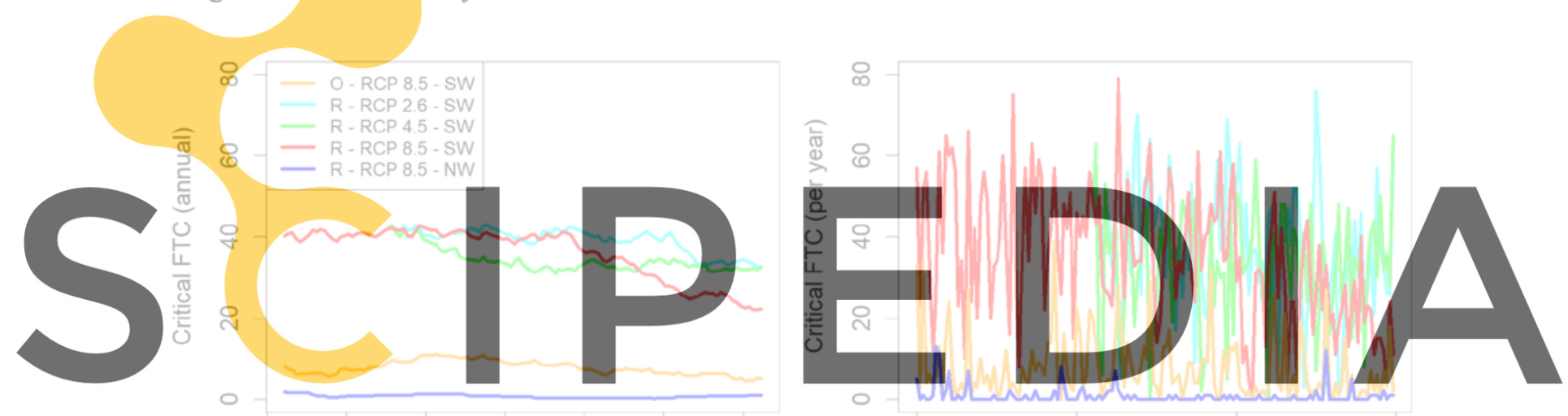

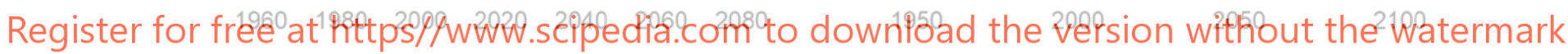
Figure 3. Moving average of the annual number of critical freeze-thaw cycles (FTC) (left) and the number of critical FTC per year (right) (O: original, R: retrofitted).

\section{Discussion}

The 'climate based' analysis illustrates that there is an increase in $\mathrm{T}_{\text {air }}$, leading to a decrease in hours of frost $\left(\mathrm{T}_{\text {air }}\right.$ ) and $\mathrm{FTC}_{\mathrm{T} \text {,air }}$ by $33 \%$ for RCP 4.5 and $66 \%$ for RCP 8.5 . This suggest that there might be a future decrease in freeze-thaw action in the brick masonry. The precipitation amount, on the other hand, is increasing over the course of the 21 st century by about $10 \%$ for RCP 4.5 and 8.5. Besides, the percentage of precipitation in winter increases, and so does the precipitation amount during that season. This means that the moisture load is distributed more towards the cold season. An increase in moisture load may increase the likelihood of the $\mathrm{MC}_{\text {crit }}$ to be exceeded in the masonry upon freezing, potentially increasing the number of $\mathrm{FTC}_{\text {crit. }}$.

The 'hygrothermal response based' analysis assesses the combined effect of the climate data with a particular wall assembly for a given orientation. Although the $\mathrm{T}_{5 \mathrm{~mm}}$ follows a similar trend compared to the climate data, there is an offset between the different trend lines depending on the wall assembly and orientation, but also on the season. As freeze-thaw action is sensitive 
to small changes in temperature, this may lead to a different number of $\mathrm{FTC}_{\mathrm{T}}$ in the masonry (Grossi et al., 2007). Therefore, also the hours of frost $\left(\mathrm{T}_{5 \mathrm{~mm}}\right)$ and $\mathrm{FTC}_{\mathrm{T}, 5 \mathrm{~mm}}$ display a significant offset per simulated case, respectively between $-25 \%$ and $20 \%$, and between $-57 \%$ and $6 \%$.

The WDR load increases by ca. $10 \%$ for RCP 4.5 and 8.5 over the 21 st century as for precipitation, and the WDR percentage and load during winter increases. However, whereas the percentage in winter is ca. $25 \%$ for the precipitation amount and slightly higher for the NWWDR load, the percentage SW-WDR load is ca. $40 \%$. The increase in percentage over the century is larger for the WDR load than precipitation amount. Thus, the distribution of moisture load in winter is underestimated by the 'climate based' analysis.

In porous materials, no freeze-thaw damage will occur regardless the number of $\mathrm{FTC}_{\mathrm{T}, 5 \mathrm{~mm}}$ if the critical degree of moisture saturation is not exceeded (Fagerlund, 1973). Therefore, the moisture management of the building envelope is a key factor when assessing freeze-thaw risk. The $\mathrm{MC}_{\text {mean,winter }}$ cannot be estimated based on only the climate data. The hygrothermal

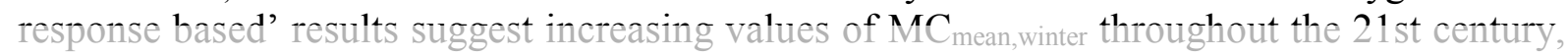
and large deviations between the simulated cases. The order of magnitude of $\mathrm{MC}_{\text {mean,winter }}$ differs with a factor up to 6 between the combinations of wall assembly and orientation.

The retrofitted SW-wall for RCP 8.5 results in $20-35 \%$ more $\mathrm{FTC}_{\text {crit, } 5 \mathrm{~mm}}$ than the original wall (same orientation). The number of $\mathrm{FTC}_{\text {crit }, 5 \mathrm{~mm}}$ remains close to zero for the retrofitted NW-

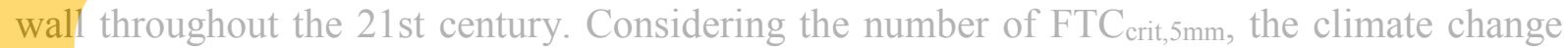
signal ranges between a decrease of $0 \%$ and $45 \%$, depending on wall assembly and orientation. This means that the decrease of 66\% in freeze-thaw action based on Tair (RPC 8.5), is mitigated by the increase in molstin orientation induce a la Future research shou signal when performing at exact threshold values such a
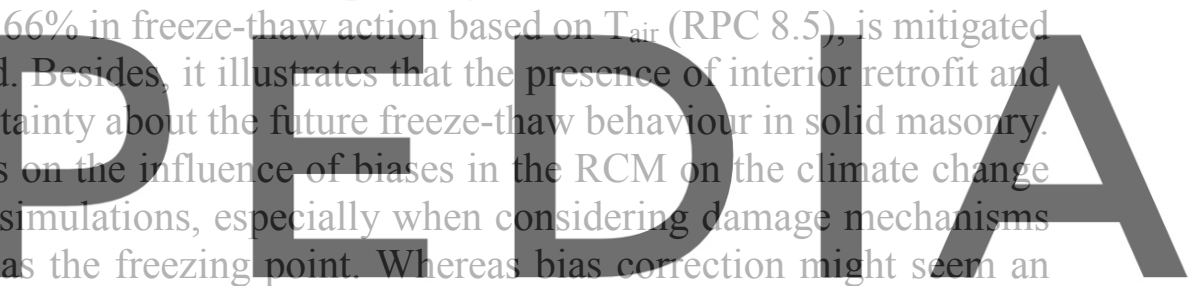

appropriate solution, this practice is not evident when dealing with the climate data for HAM

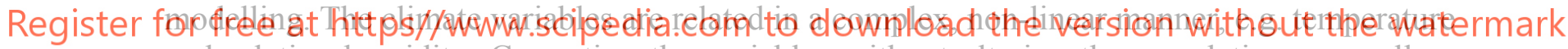
and relative humidity. Correcting the variables without altering the correlations as well as maintaining physical laws is a difficult and non-trivial practice. As an alternative to bias correction, climate model ensembles, i.e. combining data from different RCM's, are used to estimate uncertainties and manage biases. Therefore, the results presented in this paper, which only consider one RCM, will be complemented with results from different high-resolution RCM's across Belgium in future studies.

\section{Conclusion}

Frost indices based on air temperature $\left(\mathrm{T}_{\text {air }}\right)$, i.e. considering the 'climate based' analysis, suggest that there is a decrease in frost action towards the end of the 21 st century based on the ALARO-0 RCM. Both the hours of frost ( $\left.\mathrm{T}_{\text {air }}\right)$ and freeze-thaw cycles $\left(\mathrm{FTC}_{\mathrm{T}}\right.$,air $)$ are decreasing by $33 \%$ for RCP 4.5 and $66 \%$ for RPC 8.5 . Precipitation amounts are increasing by about $10 \%$ for both RCP projections, and the fraction of annual precipitation occurring in winter is increasing as well. This may lead to higher future moisture loads, increasing the likelihood for the critical moisture content to be exceeded in the masonry upon freezing. The number of critical freeze-thaw cycles at $5 \mathrm{~mm}$ depth in the masonry $\left(\mathrm{FTC}_{\mathrm{crit}, 5 \mathrm{~mm}}\right)$, resulting from the 
'hygrothermal response based' analysis, is decreasing between $0-45 \%$ depending on wall orientation and the presence of interior retrofit. It is concluded that although freeze-thaw action is reduced, the increase in moisture load could counteract this and lead to an increase in frost related damages. Besides, orientation and presence of interior retrofitting entail large uncertainties about the future freeze-thaw risk of solid masonry. Therefore, HAM simulations, i.e. 'hygrothermal response based' analyses, are required when assessing the freeze-thaw behaviour of solid masonry, before and after retrofitting, with regards to climate change.

\section{Acknowledgements}

The authors would like to thank the Belgian Royal Meteorological Institute for providing climate projections. Isabeau Vandemeulebroucke acknowledges the support of Research Foundation - Flanders (FWO) (1S90420N).

\section{ORCID}

Isabeau Vandemeulebroucke: https://orcid.org/0000-0002-7718-144X

Steven Caluwaerts: https://orcid.org/0000-0001-7456-3891

Nathan Van Den Bossche: https://orcid.org/0000-0002-8738-7249

\section{References}

Blocken, B. and Carmeliet, J. (2010). Overview of three state-of-the-art wind-driven rain assessment models and comparison based on model theory. Building and Environment, 45(3), 691-703. doi: 10.1016/ j.buildenv.2009.08.007

de Wilde, P. and Coley, Environment, 55, 1-7. för byggnadsteknik, Tekn

Fatorić, S. and Seekamp, E. literature review. Climatic Change,

Grossi, C.M., Brimblecornbe
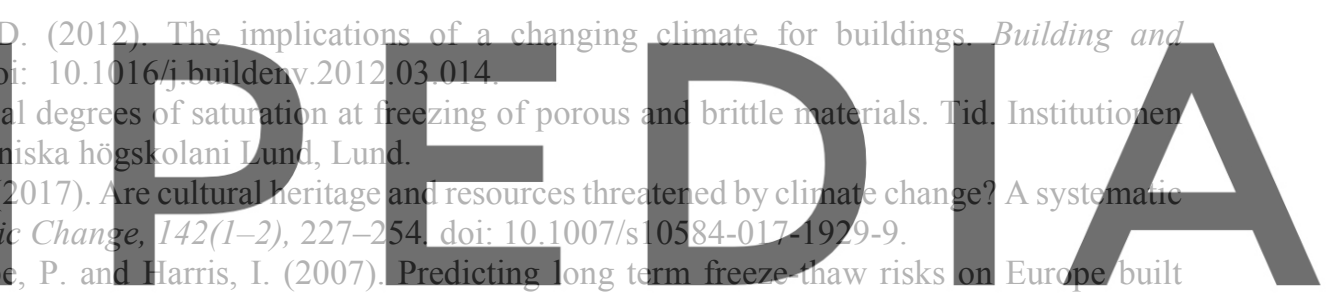
heritage and archaeological sites in a changing climate. Science of the Total Environment 377(2-3), $273-281$.

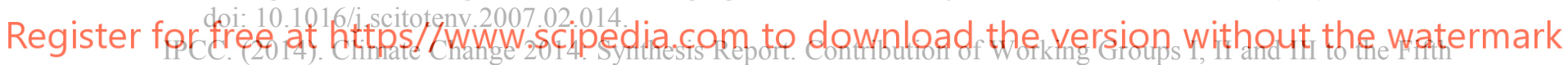
Assessment Report of the Intergovernmental Panel on Climate Change [Core Writing Team, R.K. Pachauri and L.A. Meyer (eds.)]. Geneva, Switzerland: IPCC.

Nicolai, A., Grunewald, J. and Zhang, J. J. (2007). Recent improvements in HAM simulation tools: Delphin 5 / CHAMPS-BES. In Proceedings of 12th Symposium of Building Physics, Dresden, Germany, 28-30 March 2007, 866-876.

Straube, J. and Schumacher, C. (2006). Assessing the durability impacts of energy efficient enclosure upgrades using hygrothermal modeling. Journal of the International Association for Science and Technology of Building Maintenance and Monuments Preservation, 2, 197-222.

Straube, J., Schumacher, C. and Mensinga, P. (2010). Assessing the freeze-thaw resistance of clay brick for interior insulation retrofit projects. In Proceedings of the Conference on Performances of Envelopes of Whole Buildings XI, Clearwater Beach, Florida, 5-9 December 2010. ASHRAE.

Termonia, P., Fischer, C., Bazile, E., Bouyssel, F., Brožková, R., Bénard, P. and Bochenek, B. et al. (2018). The ALADIN system and its canonical model configurations AROME CY41T1 and ALARO CY40T1. Geoscientific Model Development, 11(1), 257-281. doi: 10.5194/gmd-11-257-2018.

Vandemeulebroucke, I., Calle, K., Caluwaerts, S., De Kock, T. and Van Den Bossche, N. (2019). Does historic construction suffer or benefit from the urban heat island effect in Ghent and global warming across Europe? Canadian Journal of Civil Engineering, 46(11), 1032-1042. doi: 10.1139/cjce-2018-0594.

Vereecken, E. and Roels, S. (2013). Hygric performance of a massive masonry wall: How do the mortar joints influence the moisture flux? Construction and Building Materials, 41(4), 697-707. doi: 10.1016/ j.conbuildmat.2012.12.024. 